\title{
Continuous uptake of acoustic cues in spoken word recognition
}

\author{
PAUL WARREN \\ University of Cambridge, Cambridge, England \\ and University College London, London, England \\ and \\ WILLIAM MARSLEN-WILSON \\ Max-Planck Institute for Psycholinguistics, Nijmegen, The Netherlands \\ and MRC Applied Psychology Unit, Cambridge, England
}

\begin{abstract}
The cohort model of spoken word recognition postulates a maximally efficient uptake of acousticphonetic information during lexical access and selection. To test this, we used the gating paradigm in two experiments to measure the effects of anticipatory vowel coarticulation in word-final vowelconsonant transitions on the recognition of spoken words. In Experiment 1, we tested place contrasts between plosives and manner contrasts among plosives, nasals, and fricatives; we found a continuous effect of coarticulatory changes in vowel spectra on the process of lexical choice. In Experiment 2, we included word frequency as a variable and found that the effects of frequency operate independently of coarticulatory effects. These results are inconsistent with views of spoken word recognition that insist on discrete phoneme- or syllable-sized delays in the projection of acoustic-phonetic information onto form representations in the mental lexicon.
\end{abstract}

How is the speech input mapped onto representations of word forms in the mental lexicon? Is this a highly categorical description, in terms of complete phonemes, or can earlier access of word candidates be achieved by using partial information about the identity of a sound segment? In particular, is information derived from anticipatory coarticulation used on-line to obtain the earliest possible recognition of spoken words, as required for an optimally efficient word recognition process? In the research reported here, we investigate these questions using combined gating and splicing techniques, and taking into account the role of word frequency in the lexical interpretation of partial information.

The background for this study is the cohort model of word recognition (Marslen-Wilson \& Tyler, 1980; Marslen-Wilson \& Welsh, 1978) and its claims about the manner in which the speech input is mapped onto the representations of word forms in the mental lexicon. According to this model, the first $100-150 \mathrm{msec}$ of the acoustic-phonetic input causes the obligatory activation of an initial set of word candidates. This subset of the complete set of words in the listener's lexicon is referred to as the word-initial cohort.

The process of word recognition is defined by the model in terms of the consequences of the accumulating speech input for the membership of this initial set. As more of the speech input is heard, an increasing number of word

This research was funded by a Medical Research Council programme grant. Address reprint requests to: Paul Warren, University of Cambridge, Department of Experimental Psychology, Downing Site, Cambridge CB2 3EB, England. candidates become incompatible with this input and drop out of contention. When all candidates except one have been excluded, the remaining candidate can be recognized. The point at which this occurs (i.e., the point at which the word becomes distinguishable from all other words in the language sharing the same initial sequence) is referred to as the recognition point for that word. Much of the previous research involving the cohort model has been concerned with the psychological validity of the concept of a recognition point (e.g., Marslen-Wilson, 1980, 1984; Tyler, 1984; Tyler \& Wessels, 1983).

For the proper development of such a model, it is essential to specify fully the properties of this speech mapping process. In previous statements of the model, we sidestepped this responsibility by claiming that the process is both continuous and maximally efficient, but at the same time leaving open the question of what these claims mean in terms of the description under which the input is mapped onto the lexicon (Pisoni, 1984). In practice-but not in theory-the implementation of the theory's predictions has assumed that the input to the lexicon is a string of phonemic labels.

The model that this assumption implies, however, is not only untested, but also less than maximally efficient. The continuity of the articulatory gestures underlying the production of speech should be reflected in a truly continuous projection of the speech input onto the mental lexicon, rather than the discontinuous process imposed by the requirements of phonemic categorization.

Within the framework of standard phonemic assumptions, the nondiscreteness and the continuity of the produc- 
tion process has been dealt with by recourse to the concept of coarticulation. One major use of the term (e.g., Fowler, 1984) is to refer to the temporal overlap in the speech signal of the acoustic cues to two distinct phonetic segments. An example of this is the presence of cues to the place of articulation of a word-final plosive in the formant structure of the preceding vowel. Thus in the word scoop, the lips may move toward closure for /p/ during the vowel, whereas in scoot, the tip and body of the tongue are brought forward to form closure for the $/ t /$. Both movements, conditioned by the place feature of the consonants, produce differences in the formant frequency patterns toward the end of the vowel (see Ainsworth, 1968; F. S. Cooper, Delattre, Liberman, Borst, \& Gerstman, 1952; Liberman, Delattre, F. S. Cooper, \& Gerstman, 1954; Malecot, 1956; Stevens \& House, 1963).

Coarticulation, in this sense, is a consequence of the overlapping in the production process of adjacent segments, which is a necessary property of the articulation of speech. It can be distinguished from other types of coarticulation, such as the nasalization of a vowel prior to a nasal consonant, where the timing of the onset of nasalization is quite flexible, and may even fall under phonological control.

Although these types of coarticulation may be distributionally and functionally different, we treat them together here, since from the perspective of the cohort model, with its demands for maximal efficiency in the extraction of information from the waveform, all such effects are a potential source of information about the identity of the lexical item being uttered. The question we ask here is whether this coarticulatory information is used to guide lexical access. Early use of coarticulatory information is compatible with a model allowing partial information to drive the selection of word candidates, and not with one that permits lexical access only after input of complete phoneme-like units.

\section{Previous Research on Coarticulation}

The acoustic consequences of coarticulation have been widely studied (for reviews, see Kent \& Minifie, 1977; MacNeilage \& Ladefoged, 1976). In addition to the place feature described above, anticipatory coarticulation in a vowel can be influenced by the voicing of the following consonant (e.g., Elert, 1964; House, 1961; Klatt, 1975; Raphael, 1972), by its manner of articulation (House \& Fairbanks, 1953), and by nasality (House \& Stevens, 1956; Moll \& Daniloff, 1971). These anticipatory gestures are reflected in differences in the acoustic waveform (in durational and spectral properties) and can often precede the coarticulated segment by more than one segment (e.g., Martin \& Bunnell, 1982; Ohman, 1966).

Research on the perceptual consequences of coarticulation has almost exclusively used nonwords as stimuli. This research has shown that subjects are able to utilize coarticulatory information in making judgments about the identity of subsequent sounds (e.g., Martin \& Bunnell, 1982; Ostreicher \& Sharf, 1976; Pols \& Schouten, 1978,
1981), but does not tell us whether this information is used for the direct access of words from the lexicon.

Streeter and Nigro (1979) and Whalen (1982, 1983), however, used real words to investigate the effect on lexical access of subcategorical mismatches. Word and nonword items (e.g., soak and shoak from Whalen, 1983) were spliced so that one information source (fricative noise) did or did not match another (CV or VC spectral transitions), and so that the resulting stimulus (determined by the overriding cue of the fricative noise) was or was not a word. These auditory mismatches delayed word decisions in an auditory lexical decision task, but did not affect nonword judgments. This difference in word/nonword results implies that fine phonetic detail does affect lexical access. What it does not tell us, however, is whether there is a continuous uptake of this information during processing.

Streeter and Nigro (1979) found similar word/nonword differences in an auditory lexical decision task involving cross-spliced and deleted medial plosive and fricative transitions. They interpreted this in terms of a two-stage model of lexical access, where the lexical look-up stage is preceded by an initial processing stage. This initial processing stage, they argued, is unaffected by the acoustic quality of the signal, because otherwise the crosssplicing should affect nonwords as well as real words. Instead, the initial stage generates a whole-word representation, which is then used to search the mental lexicon (see Klatt, 1979). Thus although this is not a phonemically categorized input to the lexicon, it is a discontinuous process imposing considerable delays in the speech mapping process.

Whalen (1983) also argued for a delayed access process. In addition to the findings above, he found that initial fricatives gave the same pattern of results as did final fricatives. He took this as evidence against a disposing hypothesis (i.e., that the noise information in final position simply overrules the prior, misleading, transition information) and argued instead for the integration of phonetic information over a large stretch of speech.

However, a theory of lexical access that requires the integration of phonetic information from complete adjacent segments also fails to allow for the efficient continuous use of coarticulatory information in word recognition. It does not allow the listener to utilize coarticulatory information to determine in advance the nature of this segment, or even to narrow in on the correct analysis by excluding segments with markedly different coarticulatory effects. The notion of a maximally efficient recognition process requires that all information is exploited as it becomes available.

\section{Experimental Considerations}

To test the extent to which there is continuous uptake of temporally distributed information, the present study uses the gating task (e.g., Grosjean, 1980; Tyler \& Wessels, 1983, 1985). In the gating paradigm, words are 
presented to subjects incrementally: in the first trial of the test sequence, subjects hear, for example, only the first $50 \mathrm{msec}$ of the word; in the subsequent trial, they hear the first $100 \mathrm{msec}$; and so on in increments of $50 \mathrm{msec}$ until all of the word has been presented. After each trial they write down what they think the word is or is going to be.

The advantage of this task is that it gives us fine-grained control over the temporal extent of the sensory input that a subject hears before making a response. By using small $(20 \mathrm{msec})$ increments, we can examine in detail whether and how coarticulatory changes in the speech signal start to affect listeners' judgments about the words they are hearing. Research by Cotton and Grosjean (1984), Salasoo and Pisoni (1985), and Tyler and Wessels (1985) suggests that responses in the gating task correlate well with the timing of information uptake in more natural listening situations.

As we noted above, anticipatory coarticulation can be observed for a number of different phonetic environments. Our goal in this first study is to look at the potential lexical effects of coarticulation over a range of different environments, and for this reason we have chosen three contrasts, involving plosives, fricatives, and nasals.

The plosive pairs contrast in place of articulation, for example, in pairs like scoop and scoot. This affects the frequency trajectories of the vowel formants as closure for the stop occurs. Insofar as these vowel transitions form part of the acoustic information specifying the place of articulation of the word-final stop, then we should expect this to influence the subjects' gating choices as the vowel approaches closure, and before the final burst is heard. In terms of lexical choice, this means that the correct word (scoop or scoot) can be selected on the basis of partial information.

The other two contrast types involve a difference in the manner of articulation of the final consonant. In the second set of contrasts, plosives are contrasted with fricatives (as in spout vs. spouse). Vowel-fricative combinations are characterized by frication noise during the last few voicing periods of the vowel and by generally greater vowel duration than vowel-plosive combinations with the same voicing and place features. Again, if there is usable coarticulatory information available before the transition into noise is complete, then this should be reflected in diverging lexical choices during the gating task.

The third set contrasts plosives with nasals. The early lowering of the velum in anticipation of a nasal consonant results in nasalization of the final portion of the vowel (as in drown vs. drought). The contrast of nasal and nonnasal differs from the other two opposition types, as nasalization involves an articulator (the velum) that is independent of the articulatory configuration for the vowel. Since English has no contrastive nasal vowels, this means that a high degree of coarticulation is not only physically possible, but also is tolerated by the phonological system of the language. This leads, generally, to quite strong coarticulation, which should also be reflected in subjects' gating choices.

Experiment 1 also included a condition in which items were cross-spliced, in a manner similar to the manipulations in Whalen's $(1982,1983)$ work, to cause subcategorical mismatches between the coarticulatory information and the critical segment (critical for word identification in terms of a strict phonemic analysis). If subjects are using coarticulatory information at all, and irrespective of whether or not they are using it continuously, there should be a difference between the timing of identification for nonspliced and spliced items.

\section{Frequency}

In any study of word recognition, it is necessary to take word frequency into account. The frequency of occurrence of words has been shown to influence subjects' performance in a variety of tasks, particularly in the visual domain (e.g., Becker \& Killion, 1977; Howes \& Solomon, 1951; Solomon \& Postman, 1952), but also in the auditory domain (e.g., Blosfelds \& Bradley, 1981; McCusker, Holley-Wilcox, \& Hillinger, 1979). Within the framework of the cohort model of word recognition, word frequency differences are reflected in differential activation levels of words accessed by the initial input (Marslen-Wilson, in press). This means that the effects of frequency should be strongest during the early stages of recognition, before additional information sources influence the membership of the active cohort. Such an early transient effect has been reported (Marslen-Wilson, in press) for the influence of spoken words in priming a visual probe. Similarly, in an analysis of word candidates offered in a gating task, Tyler (1984) found a marked effect of frequency (a greater proportion of high-frequency items being given) over the initial $150 \mathrm{msec}$ of the stimuli, an effect that diminished as further sensory information accumulated. Grosjean (1980), also working with a gating task, found similar frequency biases operating before the recognition point was reached.

Given that frequency has an effect on lexical access, it is important not only to control for any possible confounding effects, but also to ask what the relation is between frequency and coarticulation effects. Do coarticulatory cues have a differential effect because of the differential activation levels of high- and low-frequency items, or do the two types of effect act independently? If there is an interaction between coarticulation and frequency, then, for example, the higher activation level of high-frequency word candidates may override coarticulatory cues to competing low-frequency candidates, giving a different pattern of effects over gating trials than for the frequency-matched stimulus pairs. Alternatively, if the effects are independent, frequency effects may be superimposed on potential coarticulatory effects, but will not change the timing of these effects.

In summary, this study investigated coarticulatory effects on word recognition and their relation to word fre- 
quency. Both aspects were included in one set of experimental materials, but are treated separately below (as Experiments 1 and 2).

\section{METHOD}

\section{Materials and Design}

Experiment 1. All of the stimuli were monosyllabic word pairs, differing only in their final consonants (e.g., scoop and scoot). Items were matched for frequency of occurrence in English, all having frequencies of under 6 per million, with an average of 2.5 per million in the Brown corpus (Kucera \& Francis, 1967).

We also controlled, as far as possible, the cohort structure of the pairs (i.e., the number of other words in the language that shared the same initial sequence). We were able to find 13 unique pairs where no other items had the same initial $\mathrm{C}(\mathrm{C}) \mathrm{V}$ sequence. The other 11 pairs were all selected from low-frequency clusters where none of the other items in the cohort were of higher frequency than the test items. The mean cluster size was 3.14 , including the unique pairs.

A total of 24 pairs of items were used, 8 in each of three categories of phonetic opposition in the final consonant: plosive-plosive pairs contrasting in place of articulation (e.g., scoop-scoot), plosivefricative pairs contrasting in manner of articulation (e.g., spoutspouse), and plosive-nasal pairs contrasting in manner (e.g., drought-drown). The scarcity of low-frequency plosive-fricative and plosive-nasal pairs in the language meant that the test pairs could not be matched on all phonetic dimensions. Thus some items in these two conditions differ in place of articulation as well as in manner (e.g., pulp-pulse, swoop-swoon)

After splicing, each of these 24 pairs produced four versions (two unspliced and two spliced). These versions were distributed over four stimulus tapes, such that each tape contained six items in each condition, with two items within each condition from each of the three phonetic contrasts.

Experiment 2. The second set of items consisted of matched highfrequency ( $>50$ in the Brown corpus, with a mean of 140.7 per million) and low-frequency (with a mean of 8.7 per million) pairs, taken from cohorts that otherwise contained only low-frequency items. As in Experiment 1, the stimuli consisted of place contrasts in plosives ( 8 pairs) and manner contrasts involving fricatives (6 pairs) and nasals (6 pairs). In each case, the direction of phonetic contrast was balanced against the direction of the high/low frequency contrast (e.g., 3 pairs testing for the effects of nasalization had the high-frequency item as the nasal, whereas 3 had a non-nasal highfrequency item compared with a low-frequency nasal).

The 20 pairs of frequency-contrasted items were included in the four stimulus tapes produced for Experiment 1. Each tape contained 10 high- and 10 low-frequency items from these pairs, and Tapes 1 and 3 had the same selection of items (as did Tapes 2 and 4). Thus there were twice as many responses for this set as for the first set of materials.

\section{Procedure}

The test items were recorded by one of the experimenters in a soundproof booth onto audio tape (using a Revox B77 tape deck). They were then digitized at $20 \mathrm{kHz}$ (after analog lowpass filtering at $15 \mathrm{kHz}$ ) and stored on computer disk. The splicing and generation of stimulus sequences was performed on these stored waveforms.

The splicing procedure requires certain assumptions about where exactly the critical segment starts, which is part of a segmentation problem familiar to all speech researchers (see Fowler, 1984). This problem goes hand in hand with the problem of coarticulation, since it is the coarticulation of segments that makes it difficult to determine where a phonemic segment begins and ends. The approach taken toward this problem in the current study is as follows. For each item, an alignment point was designated, which corresponded to the phoneme boundary as used, for example, in durational measurements of speech wave data (Cooper \& Paccia-Cooper, 1980; Klatt, 1975; Peterson \& Lehiste, 1960; Umeda, 1977). For the first set of items, this point served as the splicing point, and for all items the alignment point was at the end of a gate.

The alignment points were defined here according to the procedures illustrated in Figure 1. For plosive items, the offset of the vowel before closure is a clearly distinguishable feature (see Figure 1A). Figures 1B and 1C show the situation for vowelconsonant boundaries when the consonant is a fricative or a nasal. For fricative items, the alignment point was defined as the midpoint between the onset of frication in the vowel and the offset of voicing in the fricative (fricatives were voiceless). For nasal items, it was a midpoint between where vowel formants begin to be smoothed out and where the formant peaks have clearly disappeared. All points were measured from the digitized waveform displayed on a high-resolution Hewlett-Packard monitor. Although there is inevitably a subjective component to the judgments involved in making these measurements, the alignment points can be consistently determined, across items of a similar type, to within one pitch period $( \pm 10 \mathrm{msec})$.

The alignment points were used first to construct the spliced materials. The spliced versions of each pair of items were constructed by joining the prealignment section of each member of the pair to the postalignment section of the other. The join was smoothed by imposing increasing and decreasing attenuations on the end and beginning of the two sections, respectively. The sections were then added to one another so that the overlap crossed at the $50 \%$ attenuation point of both sections, which was also the alignment point.

The construction of the gating materials was also controlled by the alignment points assigned to each item. The first segment for each sequence included the entire word up to a point $80 \mathrm{msec}$ before the alignment point. The sequence of test-items (spliced and nonspliced) then proceeded in 20-msec increments from this point. This meant that the fifth gate that the subjects heard for each item terminated at the alignment point. For plosive pairs, some of the gates spanning the closure were omitted, as they added only silence. The last 2 msec of each gate was windowed to produce an accelerating attenuation that eliminated audible clicks (see Ohde \& Sharf, 1981; Pols \& Schouten, 1981).

The sequences of items were recorded from disk onto audiotape using the equipment mentioned above, with 5 -sec intervals between items within a sequence and $10 \mathrm{sec}$ between sequences. Each sequence was cued by a series of three tones, each item by a single tone. The test items were preceded by five practice items, after which the procedure was discussed. Subjects were required to write on response sheets (one for each sequence) the word they thought they had heard and the confidence (on a scale from 1 to 9) of their judgment. Scale point 1 corresponded to the label pure guess and point 9 to the label totally confident.

\section{Subjects}

Ten different subjects were tested on each tape, giving 10 response sets for frequency-balanced and 20 sets for frequency-contrasted stimuli ( 4 additional subjects were replaced because of incomplete response sheets). The 44 subjects were paid undergraduate and graduate volunteers from the University of London.

\section{RESULTS AND DISCUSSION}

\section{Experiment 1: Frequency-Matched Stimuli}

Of the 24 word pairs tested in this experiment, 3 had to be omitted from the analyses. In two cases this was because of insufficient correct responses and in the third because of an error in the experimental design. ${ }^{1}$ 

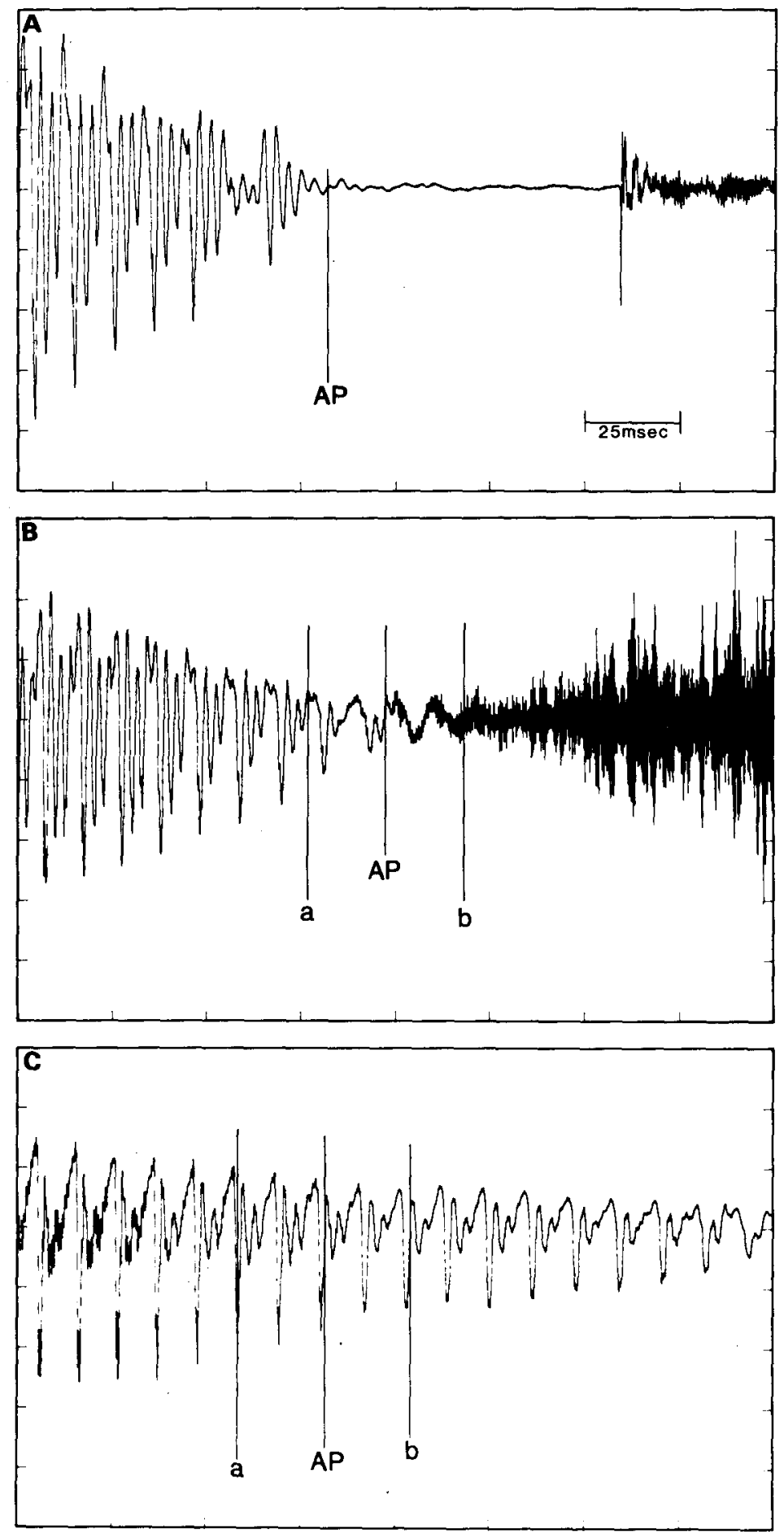

Figure 1. Alignment points (AP) assigned to the stimulus types used in the gating experiments. In Figure $1 \mathrm{~A}$ the offset of voicing periods of the vowel on closure for the voiceless plosive is marked for stimulus swoop. Figures $1 B$ and $1 \mathrm{C}$ show the use of midpoint measures for transitions to voiceless fricatives and nasal consonants, respectively. In 1B (sluice) the points used to derive the AP are the onset of frication in the vowel (a) and the ofiset of voicing in the fricative (b). In $1 \mathrm{C}$ (flown) the AP is the midpoint between the point where vowel formants begin to be smoothed out (a) and the point where they have disappeared (b). 
Overall effects. The question of whether coarticulation has an effect can be answered by looking at the overall effects of the splicing manipulation on the timing of word identification. The gating task provides two global measures of this.

First, we can determine the amount of input that is necessary for subjects to isolate the correct word from the rest of the active cohort (i.e., to respond with the correct item without subsequently changing their minds). The point at which $80 \%$ of the subjects do this is known as the isolation point for a given item (see Grosjean, 1980). This is typically at a stage in the accumulating speech signal where the evidence for the correct word is still relatively weak, and where other candidates may still be possible. This is often reflected in the subjects' low confidence in their judgments at this point.

The second measure of word identification sets a stronger criterion. It requires not only that $80 \%$ of the subjects have identified the word, but also that they are at least $80 \%$ confident in this judgment. This is called the recognition point and reflects the point in the signal at which the identity of the stimulus has become completely clear. Research by Tyler and Wessels (1983) shows that the recognition point measured in this way corresponds very well to the recognition point predicted by the cohort model.

The use of these two measures, in summary, allows us to evaluate the timing with which stimulus information emerges in different coarticulatory contexts, from the in- itial indication of the correct candidate to its final identification. The analysis of isolation and recognition points for the frequency-matched stimuli under the two splicing conditions is displayed in Figure 2. All identification points are given relative to the splicing alignment point at the end of the fifth gate.

Three effects are shown in Figure 2. One is the difference between isolation and recognition points. Another is the effect of the different type of final consonant. The third and most important is splice, which contrasts identification times for spliced and nonspliced items. Thus, for example, a nonspliced item with a final fricative, such as spouse, would be contrasted with a spliced item constructed by combining the initial CCV sequence from spout with the fricative from spouse. The spliced items serve, therefore, to bring the coarticulatory information available early in the sequence into potential conflict with the additional phonetic information in the postsplice section. ${ }^{2}$

Separate three-way ANOVAs were carried out on the subject $\left(\mathrm{F}_{1}\right)$ and item $\left(\mathrm{F}_{2}\right)$ means and were then combined to yield $\min F^{\prime}$ values (all $F$ values reported are significant at the .05 level or above, unless otherwise noted). First, there was a strong main effect of point $\left[\min F^{\prime}(1,48)=64.23\right]$, with the recognition point falling an average of $47 \mathrm{msec}$ later than the isolation point. The size of this effect interacts with the splice variable $\left[\min F^{\prime}(1,43)=4.1\right]$. Cross-splicing has a stronger effect on isolation point than on recognition point, because

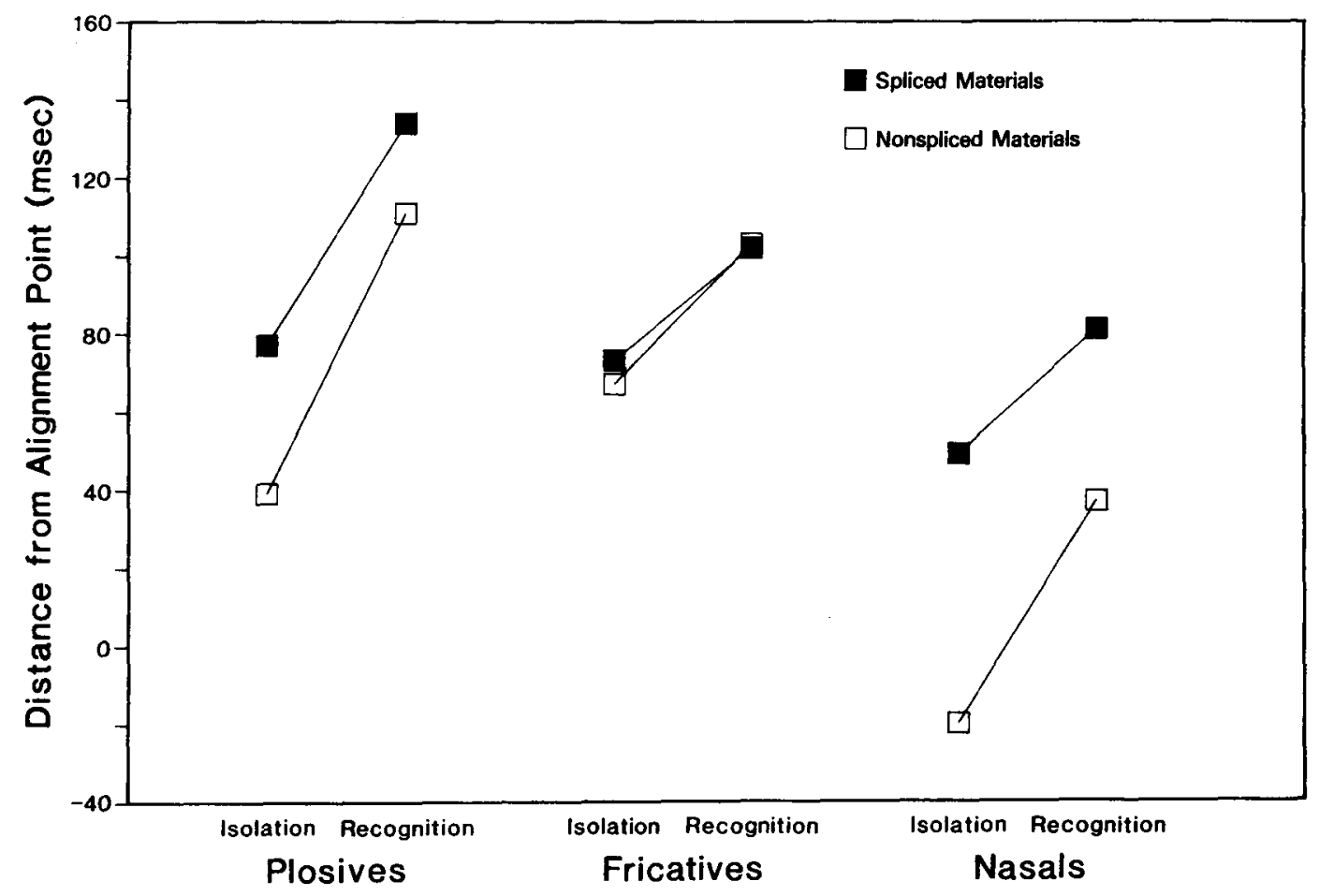

Figure 2. Isolation and recognition points computed for plosive, fricative, and nasal stimuli in Experiment 1. Open symbols indicate nonspliced materials; closed symbols indicate the effect of splicing inappropriate C(C)V sequences onto the final $C$. 
splicing is more disruptive of the preliminary cues to word identity, which tend to fall before the alignment point. It has less effect on the stronger cues (e.g., stop release, frication noise) that fall later in the sequence, those cues on which the recognition point is primarily based.

The splice variable also interacts with stimulus type $\left[\min F^{\prime}(2,33)=3.60\right]$. In particular, it has no effect on the identification of fricatives. This suggests that there is no perceptually useful coarticulatory information in the vowel preceding the onset of frication. In contrast, as reflected in the significant main effect for splice $\left[\min F^{\prime}(1,51)=14.94\right]$, the identification of both plosive and nasal stimuli is significantly impaired in the splicing condition, demonstrating a perceptual role for the coarticulatory information falling before the alignment point.

Finally, there is a main effect for type $\left[\min F^{\prime}(2,30)=\right.$ 5.80]. This reflects the consistently earlier isolation and recognition points for the nasal stimuli, relative to the alignment point.

Effect over time for three phonetic contrasts. The overall effects of splicing show that coarticulatory information is used to determine the identity of words terminating in plosives and nasals. By looking at the candidates offered at each gate, we can analyze in detail the time course of these effects. Figures 3, 4, and 5 show, respectively, the proportions of plosive, fricative, and nasal responses given as candidates at each gate under each splicing and stimulus combination for the respective stimulus sets. These figures give a reasonably complete picture of the way in which the information associated with different vowel-consonant pairings becomes available over time and is used to guide lexical choice. Note that the five gates leading up to the alignment point are the crucial area for the observation of potential coarticulatory effects.

Figure 3 plots the results for one member of each plosive pair (referred to here as plosive 1 , or $\mathrm{P} 1$; the second member of each pair is referred to as P2; note that for different subject sets, the same stimulus could be either P1 or P2). It shows that the use of coarticulatory information for place of articulation of plosives (vowelconsonant formant transitions) increases across gates toward the alignment point (zero on the horizontal axis). P1 responses to appropriately coarticulated items (P1-P1 and P1-P2) increase steadily up to the alignment point. From 120 msec after the alignment point, stop release information becomes available, resulting in a drastic increase in correct scores for words for which the release is appropriate (P1-P1 and P2-P1) and a reduction for the others. The change is initially more conservative for spliced items, showing a mismatch effect (of transitions and release) that disappears after further presentations.

Figure 4 confirms the absence of coarticulatory cues to frication for our stimuli. Virtually no fricative responses, whether appropriate or not, are given until some $40 \mathrm{msec}$ after the alignment point (the onset of frication noise). Thereafter, the fricative scores increase rapidly, and almost equally for spliced and nonspliced materials.

The effects of coarticulation and splicing are seen most clearly for nasals, as shown in Figure 5. Items originally from nasal-final words (N-N and N-P) receive higher nasal

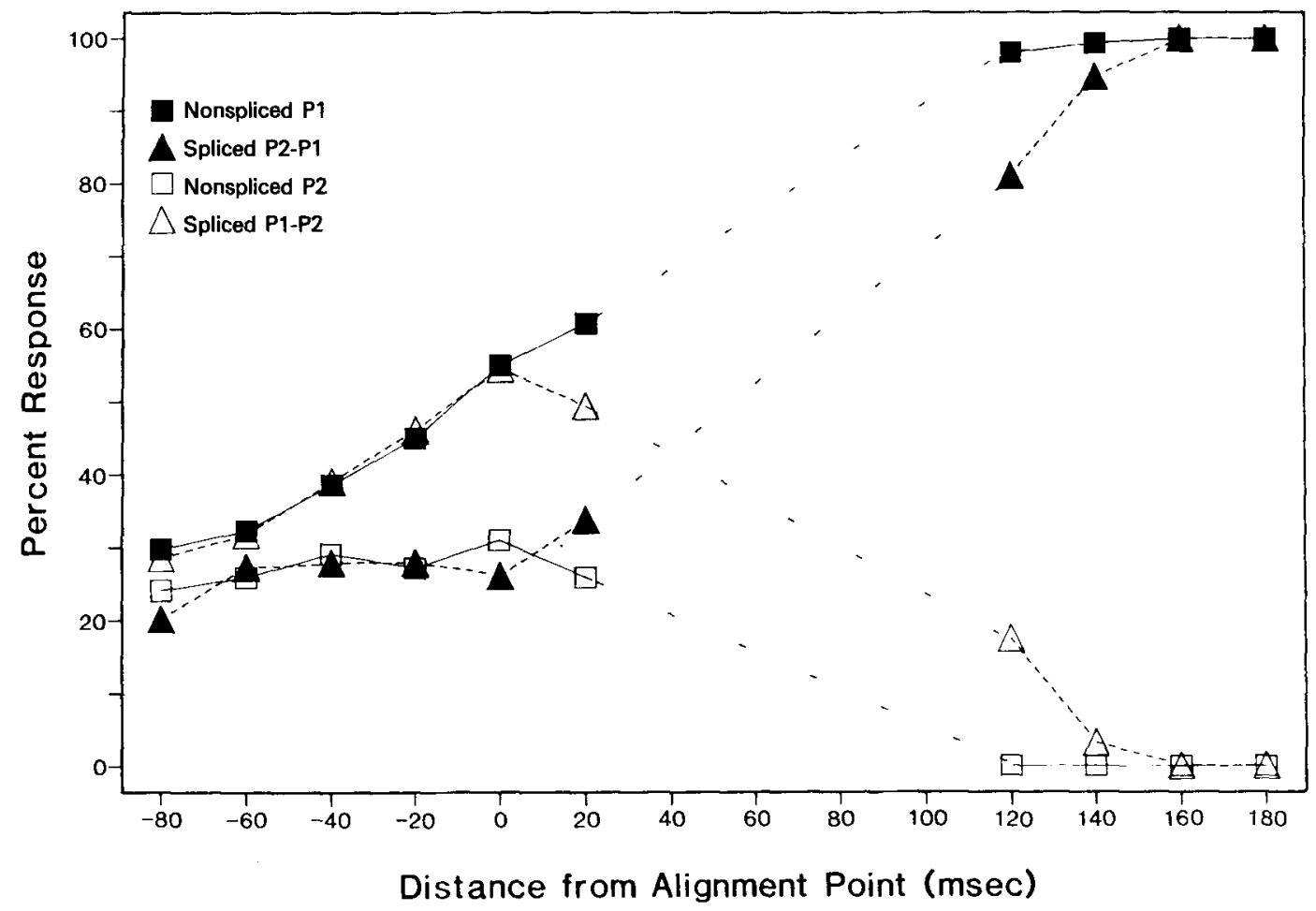

Figure 3. Percent P1 (plosive1) responses by gate to plosive stimuli in Experiment 1, according to whether the stimulus was nonspliced P1 (e.g., scoot) or P2 (scoop) or spliced P2-P1 $(\operatorname{scoo}(p)-t)$ or P1-P2 (scoo $(t)-p)$. 


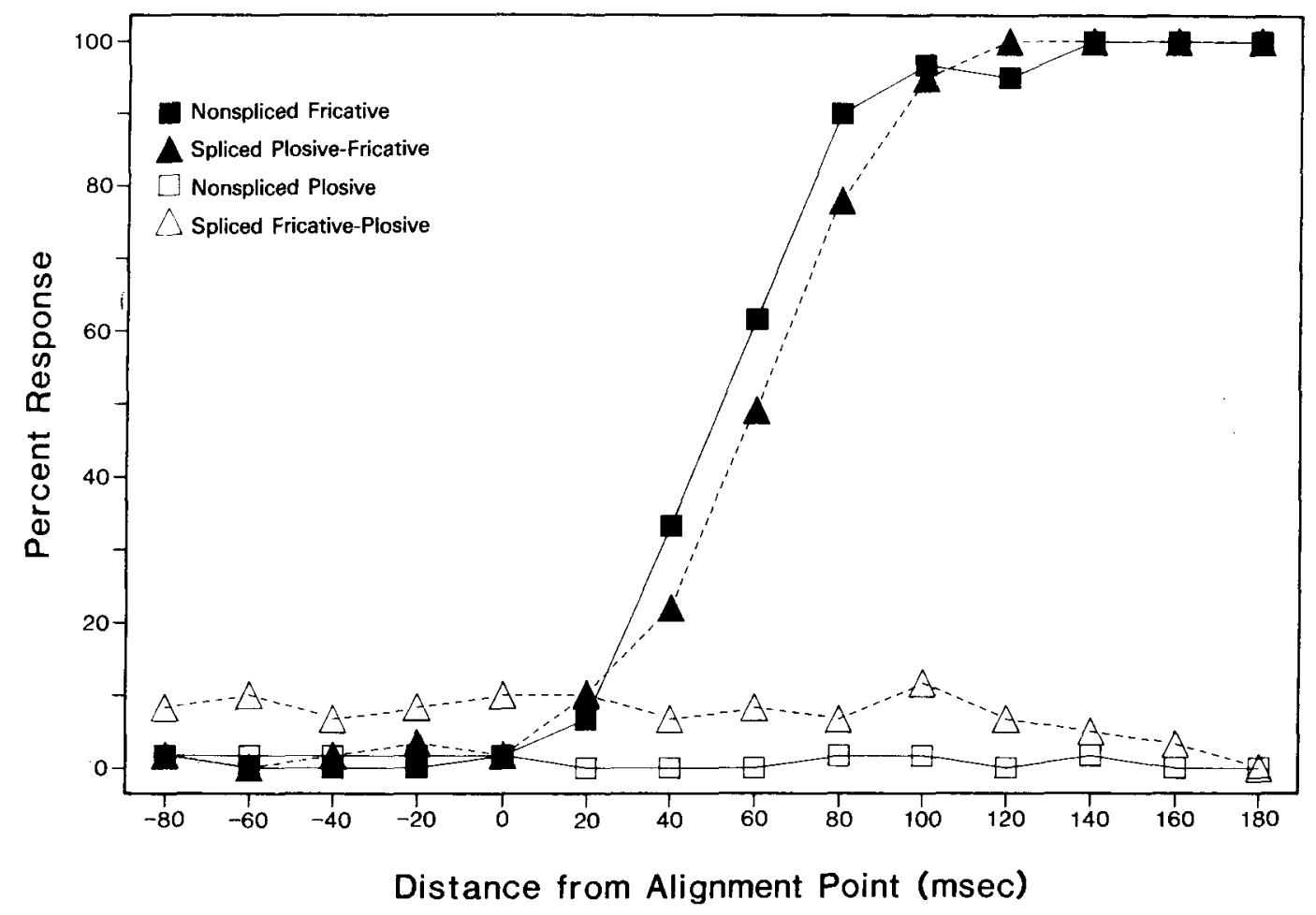

Figure 4. Percent fricative responses by gate to fricative-plosive pairs in Experiment 1, according to whether the stimulus was nonspliced fricative (spouse) or plosive (spout) or spliced plosive-fricative $(s p o u(t)$-se) or fricative-plosive $(\operatorname{spou}(\mathrm{se})-t)$.

scores over the first gates, whereas non-nasalized vowels show a drop in responses favoring the final nasal consonant. As with plosive items, there is a switch-over in responses for the spliced items after the splicing point, although responses for the N-P sequences remain high until the plosive release burst is heard (100-120 msec after the alignment point. The lack of nasalization on the vowel in P-N results in lower nasal scores than for N-N until some $160 \mathrm{msec}$ after the alignment point. ${ }^{3}$

To evaluate statistically the effects of coarticulation over the crucial five gates up to and including the alignment point (i.e., from -80 to $0 \mathrm{msec}$ ), we analyzed the correct plosive, fricative, and nasal responses for each gate, collapsing across spliced and nonspliced versions (see Figure 6). There were significant main effects of both type $\left[\min F^{\prime}(2,31)=6.24\right]$ and gate $\left[\min F^{\prime}(4,183)=9.58\right]$. Conducting trend analyses on the gate scores within each type, we found significant linear effects for the plosive contrast $\left[\min F^{\prime}(1,20)=11.91\right]$, linear $\left[\min F^{\prime}(1,21)=\right.$ $4.04]$, and quadratic $\left[\mathrm{min} F^{\prime}(1,37)=5.80\right]$ effects for the nasal contrast, and no effects of gate for the fricative contrast. Overall, post hoc comparisons show that both plosives and nasals differ significantly from fricatives, but that they do not differ from each other.

Competitor effects and coarticulation. According to the cohort model, the identification of a given word reflects not only the evidence for that word itself, but also the evidence that other words (i.e., the other members of the word-initial cohort) are not present. The timing of word identification depends, therefore, on how far the evidence favoring a given word candidate also favors other possible candidates. To the extent that a word has competitors, its isolation and recognition are delayed.

It is possible to test this claim here, because equivalent plosive stimuli are paired with three different kinds of competitors: other plosives, fricatives, and nasals. Consider, for example, the pairs scoop-scoot and swoopswoon and, in particular, the $80 \mathrm{msec}$ of vowel preceding closure for scoop and for swoop. The degree of anticipatory coarticulation of the $/ \mathrm{p} /$ in the vowel can be assumed to be the same for the two words. This means that the evidence that the word that is being heard is either scoop or swoop is the same in both cases. But the two words differ in their competitor environments. The word swoop has no plosive competitors in its cohort, whereas scoop has the close competitor scoot.

The prediction of the cohort model, given the evidence we already have for the continuous uptake of coarticulatory information, is that plosive items from the plosivenasal sets will be identified earlier and discriminated better than plosive items from the plosive-plosive sets, which have much closer competitors. The prediction for the plosive-fricative pairs is less clear, given the absence of discriminating coarticulatory information in the fricative 


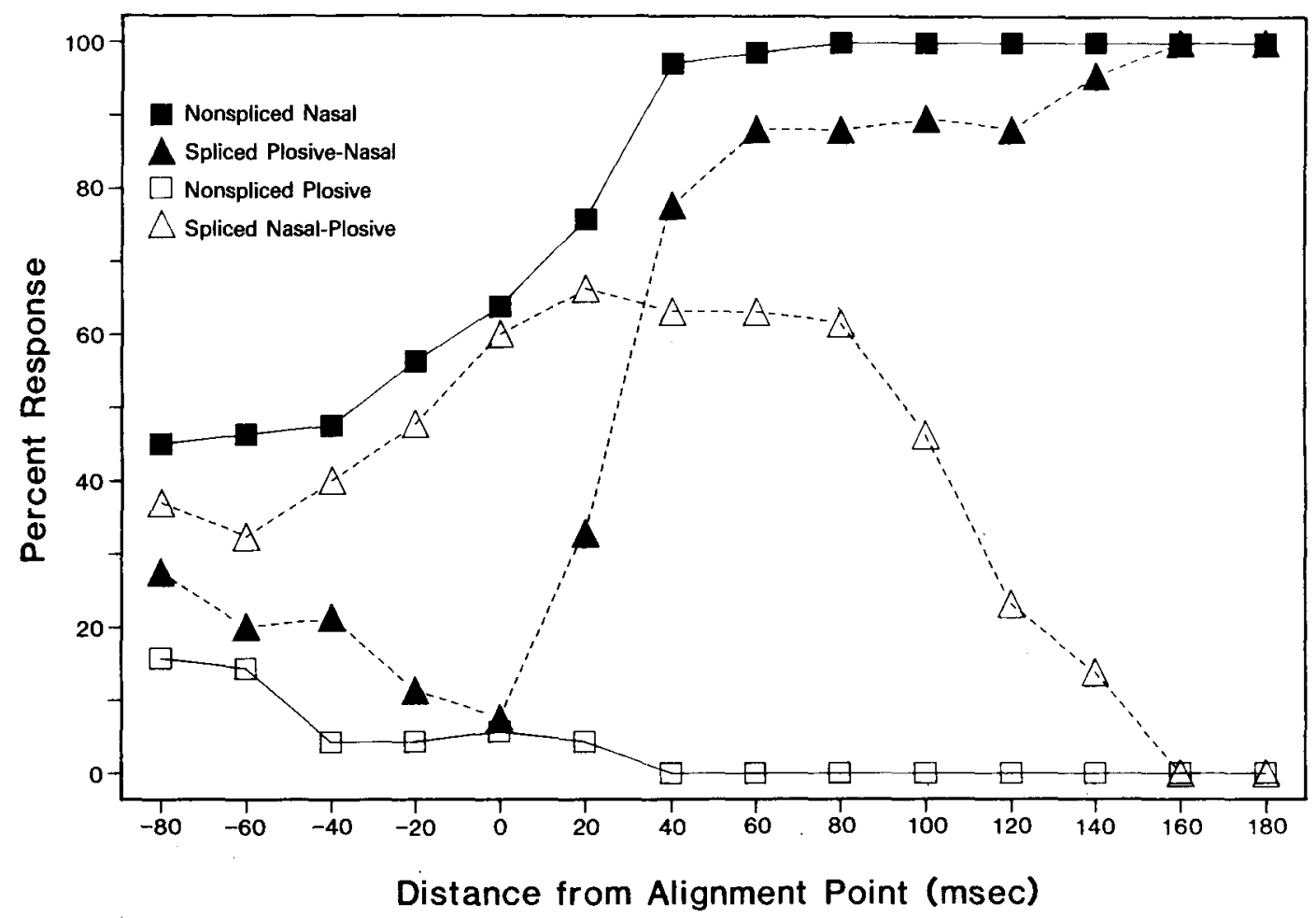

Figure 5. Percentage nasal responses by gate to nasal-plosive pairs in Experiment 1, according to whether the stimulus was nonspliced nasal (flown) or plosive (float) or spliced plosive-nasal (floa $(t)-n)$ or nasal-plosive $($ flow $(n)-t)$.

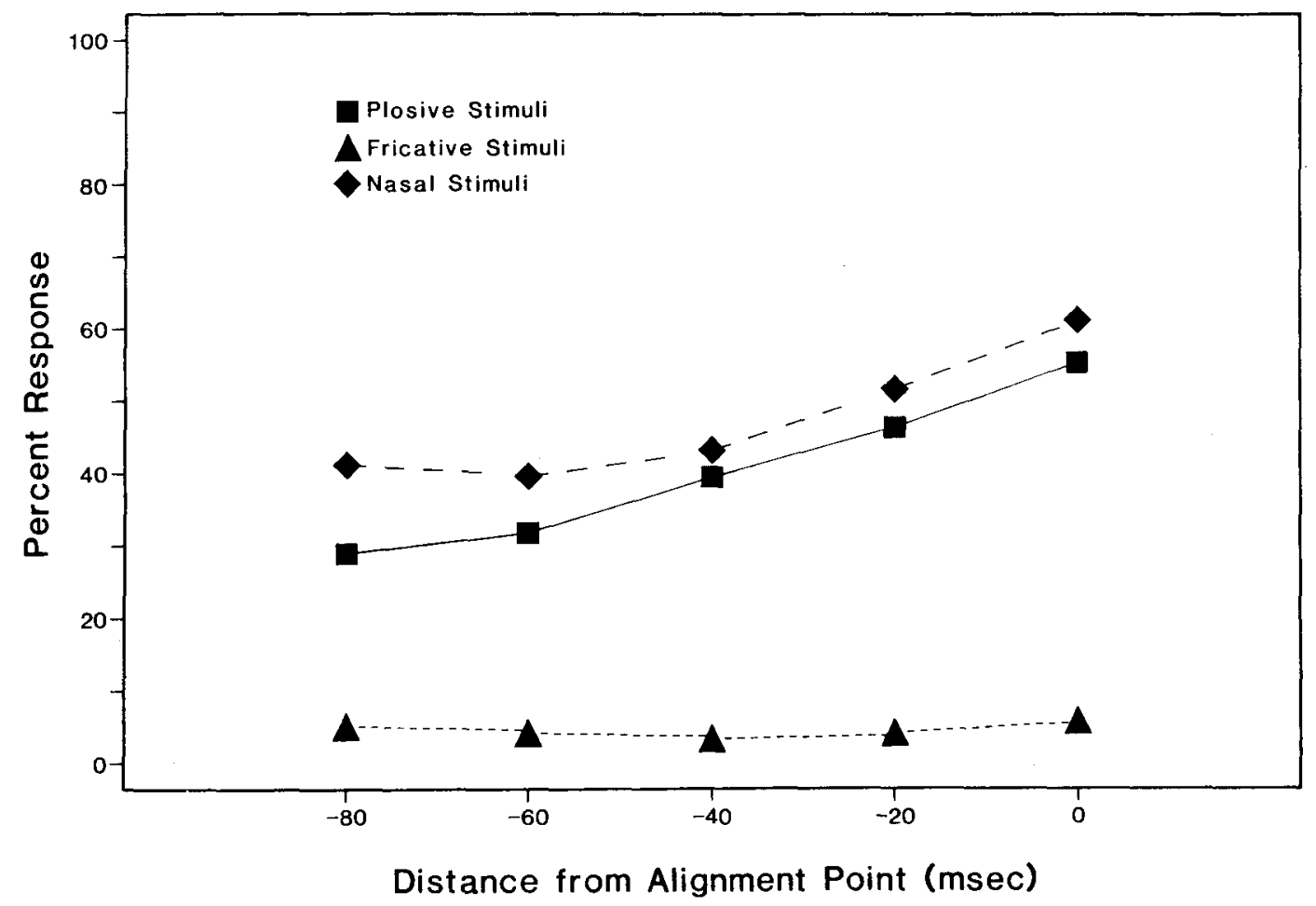

Figure 6. Percent correct plosive, fricative, and nasal responses, by gate to the alignment point, from the respective stimulus sets in Experiment 1, pooled across spliced and nonspliced versions. 
stimuli. This makes it difficult to determine when items like spout will be distinguishable from competitors like spouse in the period leading up to vowel closure.

Figure 7 displays the relevant responses. These are the correct plosive responses given to the plosive stimuli, for each of the three contrast types, for the first five gates. Note that what happens after the alignment point is not relevant here. Once the acoustic signal becomes unambiguous, then none of the stimuli have competitors any more; they have become unique.

An ANOVA confirms that there is a strong main effect of gate $\left[\min F^{\prime}(4,169)=21.13\right]$, reflecting significant linear effects over gates for all three sets of plosive responses. There is also an overall effect of type $\left[\min F^{\prime}(2,35)=2.58, p<.10 ; F_{1}(2,78)=17.63\right.$, $p<.001$; and $F_{2}(2,26)=3.02, p=.06$ ]. As post hoc tests show, the overall correct score is lower for the plosive contexts than for either the nasal or the fricative contexts. Although all three contexts start off at gate 1 $(-80 \mathrm{msec})$ with equal scores, they diverge over subsequent gates, so that, for example, at gate $4(-20 \mathrm{msec})$, the percent correct is 76.3 for the nasal context, 67.2 for the fricative context, and 46.4 for the plosive context.

This pattern of results is consistent with the claims of the cohort model. The three sets of plosive stimuli can be assumed not to differ in the strength of the coarticulatory information they contain. The goodness of fit of each plosive to its lexical form representation should not differ across sets.
Where three sets do differ is in the extent to which the listeners' mental lexicons contain other lexical form representations that are also well matched by the incoming speech signal. To the extent that they do, then the item being heard still has strong competitors as stop closure approaches. For the plosive-plosive pairs, each plosive is matched to another plosive, whereas the plosive-nasal and plosive-fricative pairs were chosen to ensure that the cohort contained no other plosive members differing only in place from the target item. This is why, as Figure 7 showed, the plosives from the plosive set were less discriminable at the alignment point than were the stimuli from the nasal and fricative sets. The chief competitor of scoop is scoot, and the initial CV from scoop is a much better match for the form representation of this plosive competitor than the initial CVs of words like swoon are for their plosive competitors.

\section{Experiment 2: \\ Coarticulation and Word Frequency}

Two stimulus pairs had to be omitted from the analysis for Experiment 2. Both of these were plosive-fricative pairs. ${ }^{4}$ Measurements of the isolation and recognition points for the remaining 18 pairs demonstrate that word frequency has an overall effect on word identification: the mean isolation and recognition points (in milliseconds from the alignment point) were 43.0 and 101.9 for lowfrequency items and $\mathbf{- 8 . 3}$ and 75.1 for high-frequency items. Analyses of variance show that, in addition to the

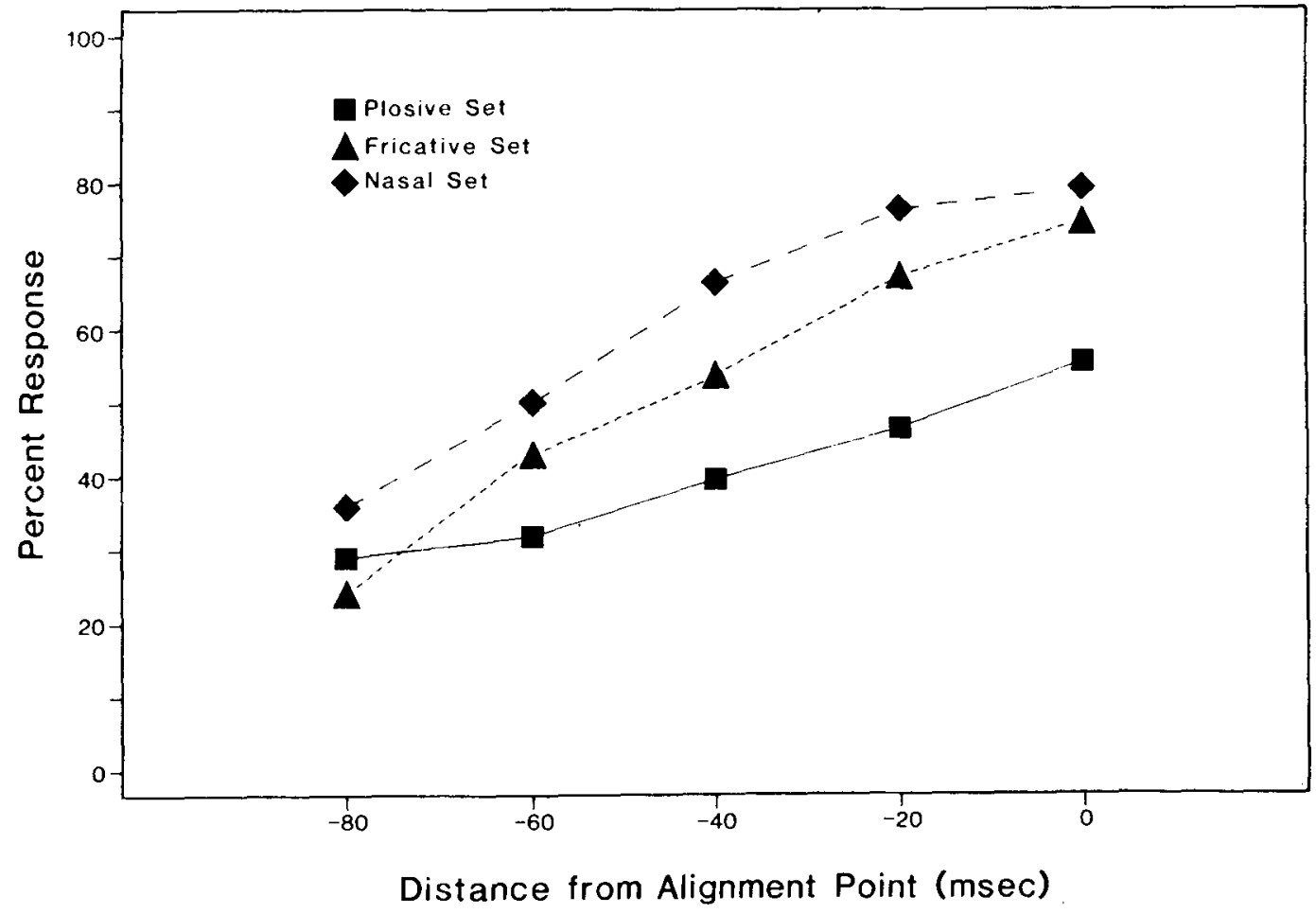

Figure 7. Percent correct plosive responses, by gate to the alignment point, to plosives from the three stimulus sets in Experiment 1 with plosive, fricative, or nasal competitors, pooled across spliced and nonspliced versions. 
main effect of type of identification point $\left[\min F^{\prime}(1,27)\right.$ $=95.72]$, there are also a main effect of frequency $\left[\min F^{\prime}(1,18)=4.28, p=.07\right]$ and an interaction between these factors $\left[\min F^{\prime}(1,25)=4.84\right]$. This is because the effect of frequency is strongest for the isolation point measure, with a 51-msec advantage for the high-frequency words, as opposed to the 26-msec effect for the recognition point measure. This is consistent with the view that frequency effects should be strongest earlier in the word.

A more detailed analysis of the temporal characteristics of the frequency effects was carried out for the item types (plosives and nasals) that produced coarticulatory effects in Experiment 1. We concentrate here on the plosive pairs. Figure 8 gives the results for the five gates up to and including the alignment point, separated into four types of response according to the correctness of the subject's answer and the frequency of the correct target. This gives us HIHI and LOLO responses, which are correct responses to high- and low-frequency targets, respectively, as opposed to the incorrect HILO and LOHI responses. HILO responses are cases in which the listener gave the high-frequency member of the pair in response to the low-frequency stimulus (e.g., giving hot as a response to the initial CV of hop). In LOHI responses, listeners gave the low-frequency response (hop) in response to the high-frequency stimulus (hot).

The results are very clear. There are two separate pairs of curves in Figure 8, each replicating the coarticulatory effects found for the frequency-matched pairs in Experi- ment 1 , and separated from each other by the effects of frequency. The upper pair of curves, for HIHI and HILO responses, plots high-frequency responses (e.g., hot) to both high- and low-frequency stimuli. The lower pair, for the LOLO and LOHI responses, plots the low-frequency responses (such as hop) to low- and high-frequency stimuli. There is a main effect of frequency $\left[\min F^{\prime}(1,16)\right.$ $=5.23 \mathrm{~J}$, but no interaction of frequency with either gate or correctness. If a word has a high frequency of occurrence, this increases the probability that it will be produced as a response at these early gates. But this effect seems to operate completely independently of the coarticulation effect.

The distribution of the frequency and coarticulation effects across gates for the plosive pairs is illustrated in Figure 9. The coarticulation curve plotted in the figure is the mean of the differences between correct and incorrect high-frequency (HIHI-HILO) and low-frequency (LOLO-LOHI) responses. Subtracting away the effects of frequency, therefore, we see a normal coarticulatory effect. ANOVAs on these scores show a strong effect of gate $\left[\min F^{\prime}(4,60)=10.57\right]$. The frequency curve, conversely, is calculated by taking the mean of the differences between the high- and the low-frequency correct (HIHI-LOLO) and incorrect (HILO-LOHI) responses. This curve indicates that there is no effect of gate, with the frequency effect remaining completely flat over gates after a small drop from gate 1 to gate 2 . This difference in the behavior over gates of the two effects is reflected

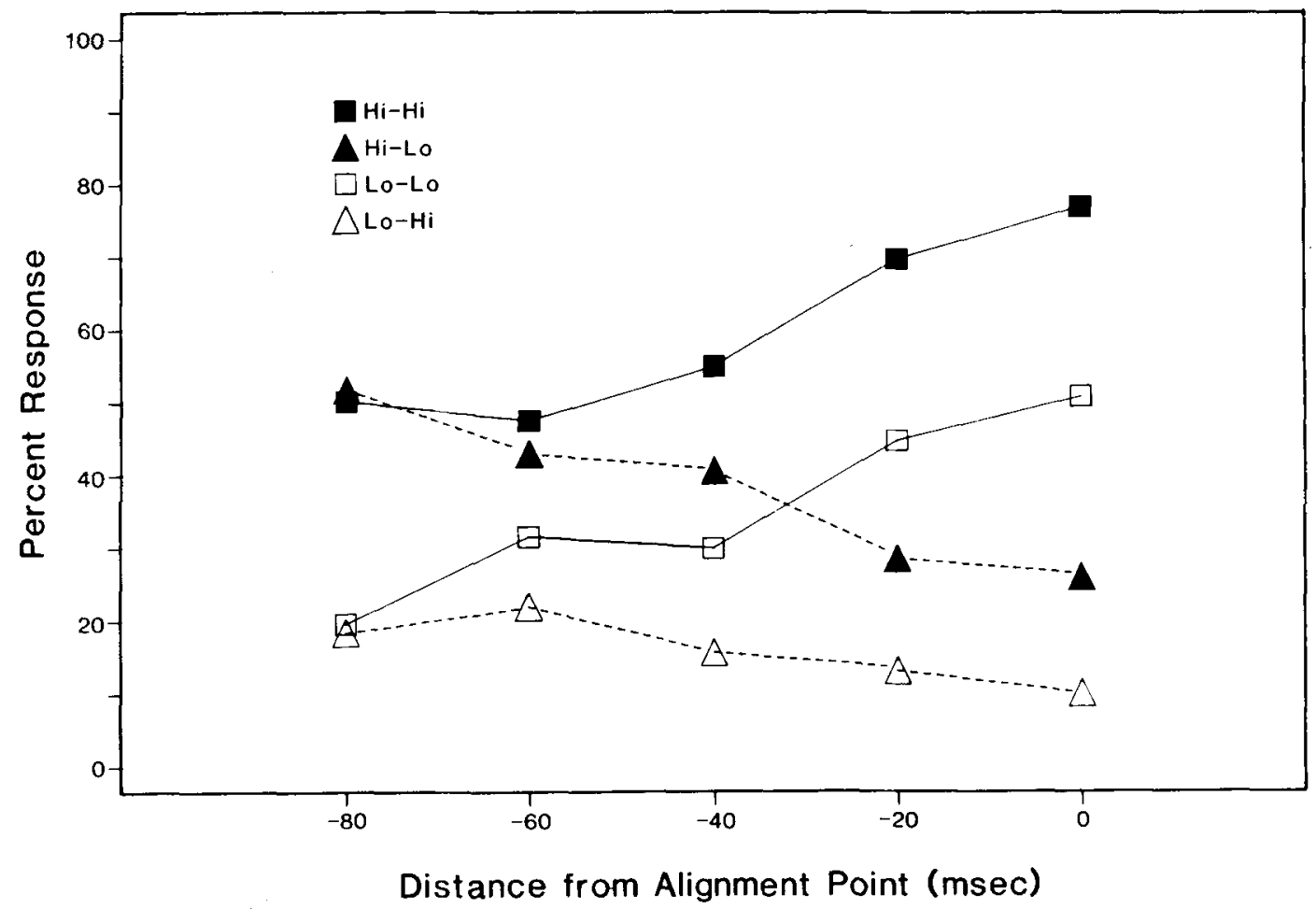

Figure 8. Percent responses, by gate to the alignment point, to plosive stimulus sets in Experiment 2, according to response and stimulus word frequency. See text for explanation of HI-HI, FI-LO, and so forth. 


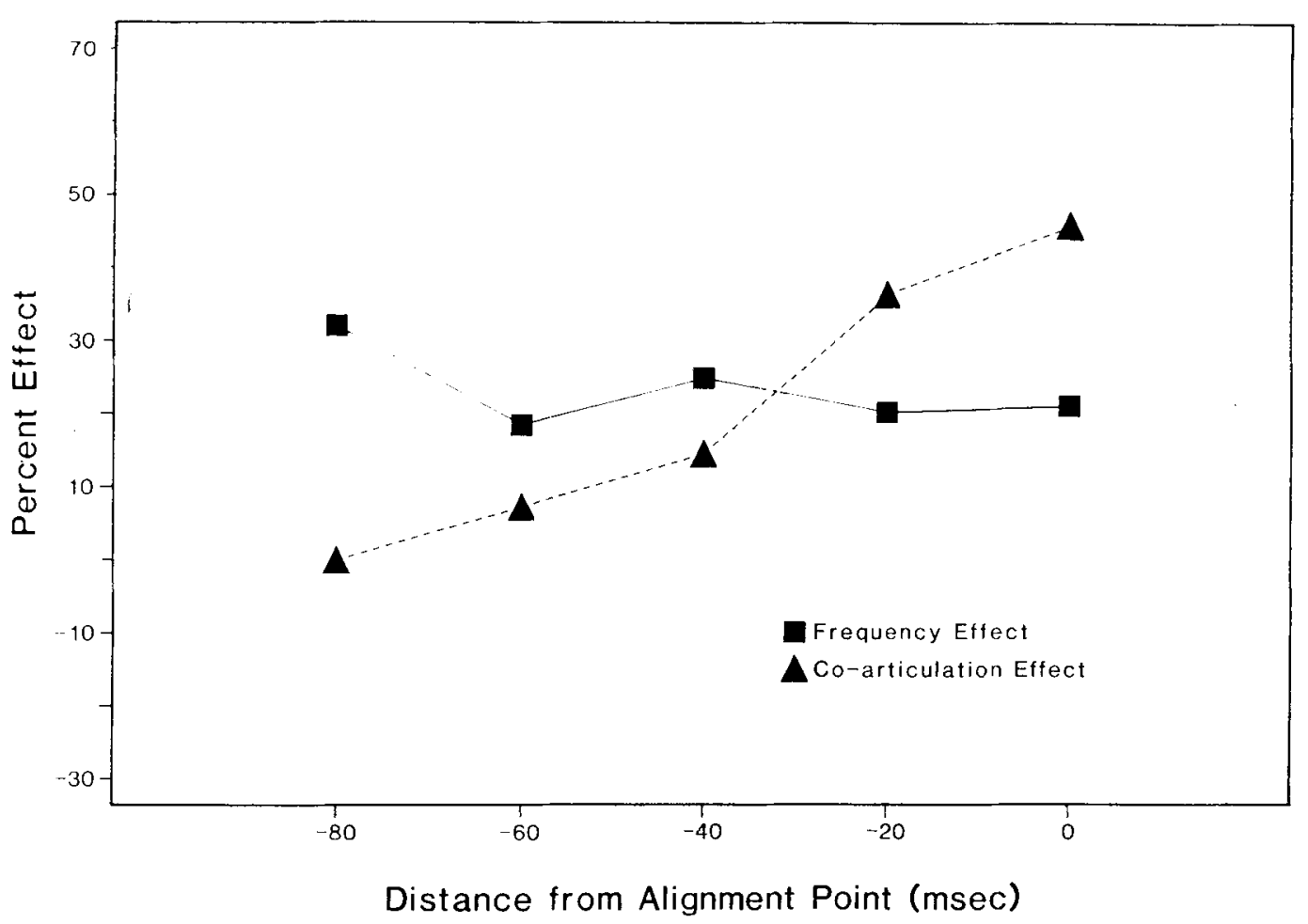

Figure 9. Derived mean frequency and coarticulation effects for plosive stimuli in Experiment 2 (see text).

in the interaction of gate and type of effect $\left[\min F^{\prime}(4,63)\right.$ $=8.19]$ in an analysis that combines both sets of derived scores. ${ }^{5}$

Turning to the questions raised in the introduction, we see that these results suggest that coarticulatory cues and the effects of frequency do not interact in determining the outcome of the recognition process. Both tasks contribute to the listeners' responses in the gating task, but they do so independently of each other. In particular, as Figure 8 shows, the effects of frequency do not override the effects of anticipatory coarticulation.

\section{CONCLUSIONS}

In this research, we asked a specific empirical question: Can information derived from anticipatory coarticulation be used on-line to obtain the earliest possible recognition of spoken words? The results clearly show that it can be. Well before the completion of the articulatory gestures and configurations associated with speech sounds such as plosives and nasals, the changes in vowel spectra determined by contrasting consonantal targets are affecting listeners' responses in the gating task. These effects, furthermore, seem to operate quite independently of the effects of word frequency.

What are the implications of this research for the wider questions raised at the beginning of the paper? First, it supports the claims of the cohort model for a maximally efficient recognition process, that is, for a recognition process that is based on a truly continuous projection of the speech input onto the mental lexicon. In fluent speech, the configuration of the vocal tract is varying more or less continuously. This produces a speech signal that is also varying continuously, and the present results are consistent with the claim for a recognition system that continuously tracks these variations.

Second, the present result is inconsistent with-although it does not completely rule out-the claim that the input to the mental lexicon is in terms of discrete units of analysis at least as large as phonemes, and possibly larger (e.g., syllables or diphones). If this is interpreted as a claim about delays in the timing with which the speech signal can start to have effects on lexical representations, then it is falsified by the current results. Given that the information about the trajectory of vowel formants is being made continuously available to the lexical level, then it is clear that the system neither waits until the appropriate segmental or phonemic label can be assigned, nor waits until the end of the processing unit relevant for the assignment of this label (e.g., until the release of a plosive).

At this point, two theoretical options are possible. One is to look for an account of the nature of lexical representations and their input that naturally allows for the continuous, nonsegmental projection of information about the speech signal onto the lexical level. The second is to look for some way of converting continuous variation in the signal into partially specified segmental information (e.g., to allow an acoustic-phonetic analysis process to continuously emit phoneme hypotheses). Neither of these can be 
excluded by the current results, and we will briefly discuss versions of each of them.

One example of a nonsegmental and potentially continuous mapping from signal onto lexicon is the type of model discussed by Klatt (1979). His LAFS (lexical access from spectra) model proposes a fine-grained analysis that projects the short-term spectral properties of the speech wave onto a level of lexical representation. Such a model allows a direct and effectively continuous mapping from the results of front-end phonetic analysis onto the lexicon. In addition, Klatt bases his implementation of LAFS upon lexical representations in terms of diphone sequences, which capture the facts of coarticulation between segments more adequately than do phoneme sequences.

An alternative approach, which holds onto the notion of a phonemic level of analysis intervening between signal and lexicon, is the implementation of a cohort-like system in the interactive activation framework by Elman and McClelland (1986). Their TRACE model of spoken word recognition allows the graded propagation up to the lexical level of partial cues to phoneme identity, thereby generating the kind of "preactivation" of phonemes that a strictly phonemic account of lexical access needs to postulate to account for our results. Even more to the point, their model directly incorporates the effects of certain types of coarticulation, through the use of a contextsensitive "weight-modulation" " procedure. Thus, for example, the pattern of feature weightings that form the input to a given consonantal phoneme node can be dynamically modulated as a function of the current vowel environment. It is this aspect of the TRACE model that Fowler (1984) takes up, on the basis of her recent research into coarticulation effects at sublexical levels.

The present results also have important methodological consequences for research on spoken word recognition. This research very often depends on the possibility of equating sets of stimuli for measurement point and for recognition point. The way that the acoustic-phonetic information necessary for word recognition is differentially distributed over the word, depending on the type of VC transition, suggests that this alignment process is much less straightforward than researchers have assumed in the past. It is difficult to see, for example, how one can align words terminating in plosives with words terminating in nasals or fricatives. Where are the informationally equivalent points in these three different manners of VC coarticulation?

We should also comment, finally, on the somewhat paradoxical relationship between the notion of alignment point, as we have used it here, and the evidence that we have adduced for the role of anticipatory coarticulation in spoken word recognition. In a certain sense, this evidence is an artifact of the positioning of the alignment point, since the concept of an alignment point is itself arbitrary, as stressed in the discussion of segment boundaries in the Method section. But at the same time, it should not be forgotten that the alignment points we actually chose are not, in fact, historically arbitrary. They are all points that have an established conventional significance in phoneme-based research on how the signal carries information.

The crucial point arising from the present experiments is that the signal changes over time, and that the process of lexical choice tracks these changes continuously and in detail. From this perspective, the alignment point does not have any special independent status, but at the same time it is not arbitrary. Its function and its methodological usefulness are that it is an appropriate central reference point, relative to which we can measure the perceptual consequences of the VC transition.

\section{REFERENCES}

AINsworth, W. A. (1968). Perception of stop consonants in synthetic CV syllables. Language \& Speech, 11, 139-155.

Becker, C. A., \& KILLION, T. H. (1977). Interaction of visual and cognitive effects in word recognition. Joumal of Experimental Psychology: Human Perception \& Performance, 3, 389-401.

Blosfelds, M., \& BRADley, D. C. (1981, November). Visual and auditory word recognition: Effects of frequency and syllabicity. Paper presented at the Third Australian Language and Speech Conference, Melbourne University.

Cooper, F. S., Delattre, P., Liberman, A. M., Borst, J. M., \& Gerstman, L. J. (1952). Some experiments on the perception of synthetic speech sounds. Journal of the Acoustical Society of America, 24, 597-606.

CoOper, W. E., \& Paccia-Cooper, J. (1980). Syntax and speech. Cambridge, MA: Harvard University Press.

CotTon, S., \& GrosjeAn, F. (1984). The gating paradigm: A comparison of successive and individual presentation formats. Perception \& Psychophysics, 35, 41-48.

ELERT, C.-C. (1964). Phonological studies of quantity in Swedish. Stockholm: Almqvist and Wiskell.

Elman, J. L., \& MCClelland, J. L. (1986). Exploiting lawful variability in the speech wave. In J. S. Perkell \& D. H. Klatt (Eds.), Invariance and variability in speech processes. Hillsdale, NJ: Erlbaum.

Fowler, C. A. (1984). Segmentation of coarticulated speech in perception. Perception \& Psychophysics, 36, 359-368.

Grosiean, F. (1980). Spoken word recognition processes and the gating paradigm. Perception \& Psychophysics, 28, 267-283.

House, A. S. (1961). On vowel duration in English. Journal of the Acoustical Society of America, 33, 1174.

House, A. S., \& Falrbanks, G. (1953). The influence of consonant environment upon the secondary characteristics of vowels. Journal of the Acoustical Society of America, 25, 105.

House, A. S., STEVENS, K. N. (1956). Analog studies of the nasalization of vowels. Journal of Speech \& Hearing Disorders, 21, 218-237.

Howes, D., \& Solomon, R. (1951). Visual duration thresholds as a function of word probability. Journal of Experimental Psychology, 41, 401-410.

KENT, R. D., MINIFIE, F. D. (1977). Coarticulation in recent speech production models. Journal of Phonetics, 5, 115-133.

KLATT, D. H. (1975). Vowel lengthening is syntactically determined in a connected discourse. Journal of Phonetics, 3, 129-140.

KLATT, D. H. (1979). Speech perception: A model of acoustic-phonetic analysis and lexical access. Journal of Phonetics, 7, 279-312.

KuČERA, H., \& Francis, W. N. (1967). Computational analysis of present-day American English. Providence, RI: Brown University Press.

Liberman, A. M., Delattre, P. C., Cooper, F. S., \& Gerstman, L. J. (1954). The role of consonant-vowel transitions in the stop and nasal consonants. Psychological Monographs, 68(8, Whole No. 379).

MacNeilage, P. F., Ladefoged, P. (1976). The production of spech 
and language. In E. C. Carterette \& M. P. Friedman (Eds.), Handbook of perception: Volume VII. Language and speech. New York: Academic Press.

MALECOT, A. (1956). Acoustic cues for nasal consonants. Language, 32, 274-284.

MARSLEN-WiLson, W. D. (1980). Speech understanding as a psychological process. In J. C. Simon (Ed.), Spoken language generation and understanding. Dordrecht: Reidel.

MARSLEN-WILSON, W. D. (1984). Function and process in spoken wordrecognition. In H. Bouma \& D. G. Bouwhuis (Eds.), Attention and performance: Control of language processes. Hillsdale, $\mathrm{NJ}$ : Erlbaum.

MarsLen-Wilson, W. D. (in press). Functional parallelism in spoken word-recognition. Cognition.

Marslen-Wilson, W. D., \& Tyler, L. K. (1980). The temporal structure of spoken language understanding. Cognition, 8, 1-71.

Marslen-Wilson, W. D., Welsh, A. (1978). Processing interactions and lexical access during word recognition in continuous speech. Cognitive Psychology, 10, 29-63.

Martin, J. G., \& Bunnell, H. T. (1982). Perception of anticipatory coarticulation effects in vowel-stop consonant-vowel sequences. Journal of Experimental Psychology: Human Perception \& Performance, 8, 473-488.

McCusker, L., Holley-Wilcox, P., Hillinger, M. (1979, April). Frequency effects in auditory and visual word recognition. Paper presented at the 25th Annual Convention of the Southwestern Psychological Association, San Antonio, Texas.

MolL, K. L., D DANilof, R. G. (1971). Investigation of the timing of velar movements during speech. Journal of the Acoustical Society of America, 50, 678-684.

OHDE, R. N., SHARF, D. J. (1981). Stop identification from vocalic transition plus vowel segments of $\mathrm{CV}$ and VC syllables: A follow-up study. Journal of the Acoustical Society of America, 69, 297-300.

OHMAN, S. E. G. (1966). Coarticulation in VCV utterances: Spectrographic measurements. Journal of the Acoustical Society of America, 39, 151-168.

Ostreicher, H. J., \& SharF, D. J. (1976). Effects of coarticulation on the identification of deleted consonant and vowel sounds. Journal of Phonetics, 4, 285-301.

Peterson, G. I., \& Lehiste, I. (1960). Duration of syllabic nuclei in English. Journal of the Acoustical Sociery of America, 32, 693-703.

PisonI, D. B. (1984).Acoustic-phonetic representations in word recognition. (Research on Speech Perception Progress Report No. 10). Bloomington, IN: Speech Research Laboratory, Indiana University.

Pols, L. C. W., SchouTEN, M. E. H. (1978). Identification of deleted consonants. Journal of the Acoustical Society of America, 64, 1333-1337.

Pols, L. C. W., \& Schouten, M. E. H. (1981). Identification of deleted plosives: The effect of adding noise or applying a time window: A reply to Ohde and Sharf. Jourmal of the Acoustical Society of America, 69, 301-303.

Raphael, L. J. (1972). Preceding vowel duration as a cue to the voicing characteristics of word-final consonants in English. Journal of the Acoustical Society of America, 51, 1296-1303.

Salasoo, A., \& Pisoni, D. (1985). Interaction of knowledge sources in spoken word identification. Joumal of Verbal Leaming \& Verbal Behavior, 24, 210-231.

Solomon, R., Postman, L. (1952). Frequency of usage as a determinant of recognition thresholds for words. Journal of Experimental Psychology, 43, 195-201.

Stevens, K. N., House, A. S. (1963). Perturbation of vowel articu- lation by consonantal context: An acoustical study. Journal of Speech \& Hearing Research, 6, 111-128.

Streeter, L. A. NiGro, G. N. (1979). The role of medial consonant transitions in word perception. Journal of the Acoustical Society of America, 65, 1533-1541.

TYLER, L. K. (1984). The structure of the initial cohort: Evidence from gating. Perception \& Psychophysics, 36, 417-427.

TYLER, L. K., \& WesseLs, J. (1983). Quantifying contextual contributions to word recognition processes. Perception \& Psychophysics, 34, 409-420.

TyLER, L. K., WEssels, J. (1985). Is gating an on-line task? Evidence from naming latency data. Perception \& Psychophysics, 38, 217-222.

UmEDA, N. (1977). Consonant duration in American English. Journal of the Acoustical Society of America, 61, 846-858.

WHALEN, D. N. (1982). Subcategorical mismatches slow phonetic judgments. Haskins Laboratories Status Report on Speech Research (Report No. SR-71/72, pp. 167-198). (Also published as Subcategorical phonetic mismatches slow phonetic judgments in Perception \& Psychophysics, 35, 49-64.)

WhaLEN, D. H. (1983). The influence of subcategorical mismatches on lexical access. Haskins Laboratories Status Report on Speech research, (Report No. SR-73, pp. 1-15).

\section{NOTES}

1. Subjects seemed unable to correctly identify either germ, which was frequently reported as journey, or pulp, which gave rise to many pole ( $p o l l$ ) responses, probably because the experimenter has very similar vowels in the two words, whereas many speakers from the same dialect background distinguish between the two. The other pair, smacksmash, was unfortunately placed on the experimental tapes after the word lack, which produced a strong bias toward the rhyming smack.

2. In referring to spliced and nonspliced items, we identify them by using such terms as nasal-plosive (N-P), plosive-fricative (P-F), and so forth. The term plosive-fricative item, for example, signifies that the initial $C(C) V$ sequence of the item was taken from a plosive-final item and the final segment from the corresponding fricative-final member of the stimulus pair. This contrasts with such terms as fricative-fricative, used for nonspliced items.

3. Although some of the fricative and nasal materials, as mentioned above, differed in place as well as in manner, this additional variation did not seem to affect the basic coarticulatory effects associated with these two manner contrasts.

4. These pairs were drop-dross and gap-gas. Drop received a large number of trop, tropics, and tropical responses, the initial consonant being misperceived as voiceless and generating a false cohort. Gas, on the other hand, gave rise to a very high proportion of gasp responses, presumably due to the shortened fricative in early gates, and despite the difference in the vowels for these two words in the speaker's dialect of British English.

5. The analysis of the nasal stimuli showed the same basic pattern of results. The coarticulatory effects matched those observed for the frequency-matched pairs in Experiment 1, with the nasal stimuli generating a strong coarticulatory effect even at the first gate. The effects of frequency were superimposed on this, and again remained effectively constant up to the alignment point.

(Manuscript received April 11, 1986; revision accepted for publication December 12, 1986.) 